\title{
Analisis SWOT dalam Pengembangan PPSDM Aparatur Menuju Corporate University
}

\author{
1st Ani Maliani \\ ${ }^{1}$ Pusat Pengembangan Sumber Daya Manusia Aparatur
}

\begin{abstract}
Increasing quality of human resources development continues to be demanded to contribute to the existence of an organization, as well as the PPSDM Aparatur which has the goal of being able to become an institutional entity as a corporate university in 2023 according to existing regulations. The aim of the research was to take the figure to what extent the PPSDM Aparatur fulfilled the components needed for the establishment of the corporate university. SWOT analysis method is conducted to find what strategic direction is needed in fulfilling those components above, which used questioner from PPSDM Aparatur employee. The result the IFAS value is 1.35 and EFAS 1.7. These two components direct the position of large organizations in quadrant I. This benefits the organization because it shows that PPSDM is strong enough and has the opportunity to lead to aggressive policies. The results of the post-education and training evaluation in 2019, which are the parameters used for training at PPSDMA as a comparison with the SWOT results show several improvements that need to be improved, such as a review of operational procedure standard training policy from planning until evaluation program. This result shows that the SWOT analysis is used as the first step in managing the strategic direction of PPSDM Aparatur towards the corporate university. However, it needs expert judgment to assess and direct the fulfillment of the company's components. so writers made of conceptual model and road map the PPSDM Aparatur corporate university in 2023 can be achieved.
\end{abstract}

\section{ABSTRAK}

Peningkatan mutu pengembangan sumberdaya manusia terus dituntut dalam upaya turut berkontribusi terhadap eksistensi suatu organisasi, begitupun PPSDM Aparatur yang memiliki cita-cita pada tahun 2023 mampu menyusun suatu entitas lembaga sebagai corporate university sesuai amanah peraturan yang berlaku. Penelitian ini bertujuan memotret sejauh mana PPSDM Aparatur memenuhi komponen-komponen yang diperlukan untuk berdirinya corporate university tersebut. Metode yang dilakukan berupa Analisis SWOT untuk melihat arah strategi apa yang dibutuhkan dalam pemenuhan komponen di atas dengan menggunakan kuesioner kepada para pegawai PPSDM Aparatur. Hasilnya menunjukan nilai IFAS 1.35 dan EFAS 1.7. Kedua komponen ini mengarahkan posisi grand strategi organisasi ada di kuadran I. Hal ini menguntungkan organisasi karena menunjukan bahwa PPSDM Aparatur cukup kuat dan memiliki peluang sehingga melahirkan kebijakan agresif. Disatu sisi hasil evaluasi paska diklat pelatihan tahun 2019 di PPSDM Aparatur yang dijadikan pembanding hasil analisis SWOT menunjukkan beberapa perbaikan yang perlu dilakukan, seperti review SOP kebijakan kediklatan perencanaan hingga evaluasi. Hal ini menunjukkan bahwa SWOT dapat digunakan sebagai langkah awal dalam mengenali arah strategi PPSDM Aparatur menuju corporate university, namun berikutnya perlu expert judgement yang menilai dan mengarahkan pemenuhan komponen-komponen tersebut seperti yang disusun penulis melalui rancangan model dan road map PPSDM Aparatur Corporate university sehingga pada tahun 2023 dapat tercapai.

\section{ARTICLE HISTORY}

Submited: 03/03/2021

Accepted: 06/03/2021

Published: 30/04/2021

\section{KEYWORDS}

Analisis SWOT, corporate university, evaluasi diklat2 SWOT analysis, corporate university, post-education evaluation 


\section{Latar Belakang}

Berdasarkan road map PPSDM Aparatur memiliki cita-cita untuk berinovasi membangun pengembangan sumber daya manusia berbasis corporate university pada tahun 2023. Hal ini dilandaskan pada peraturan Menteri Pendayagunaan Aparatur Negara dan Reformasi Birokrasi nomor 3 tahun 2020 tentang manajemen talenta aparatur sipil negara yang menjadikan ASN Corporate University (Corpu) sebagai entitas kegiatan pengembangan kompetensi ASN. Bagaimana PPSDM Aparatur dapat mencapai target tersebut, maka diperlukan usaha mengetahui informasi faktor-faktor pembentuk corporate university serta kondisi ruang lingkup penyelenggaraan pengembangan kompetensi ASN yang dilaksanakan PPSDM Aparatur saat ini melalui hasil evaluasi pasca diklat. Dari kedua informasi dapat menjadi langkah awal persiapan menuju PPSDM Aparatur corporate university 2023.

Pola pengembangan kompetensi di PPSDM Aparatur menerapkan model ADDIE (Dick dan Carey 1996) yaitu analisis, desain, development, implementasi dan evaluasi, hal ini dapat terlihat dari struktur organisasi yang memenuhi seluruh aspek model ADDIE, yaitu bidang program dan evaluasi, bidang penyelenggaraan dan sarana prasarana diklat, serta bidang perencanaan dan pelaksanaan pengembangan kompetensi. Potret penyelenggaran pelatihan PPSDMA salah satunya dapat dilihat dari hasil evaluasi pasca diklat diantaranya Diklat Teknis Pelaksana 2019, dengan informasi sebagai berikut :

- peningkatan kompetensi pada alumni diklat pada seluruh mata diklat (tertinggi 3.0, dan terendah 2.73)

- tingkat manfaat, materi pelatihan belum cukup meringankan beban kerja alumni (dibawah cut off rate 2.5 )

Gambar 1 tingkat manfaat Pelatihan Teknik Pelaksana I (Evaluasi Pasca Diklat, 2019)

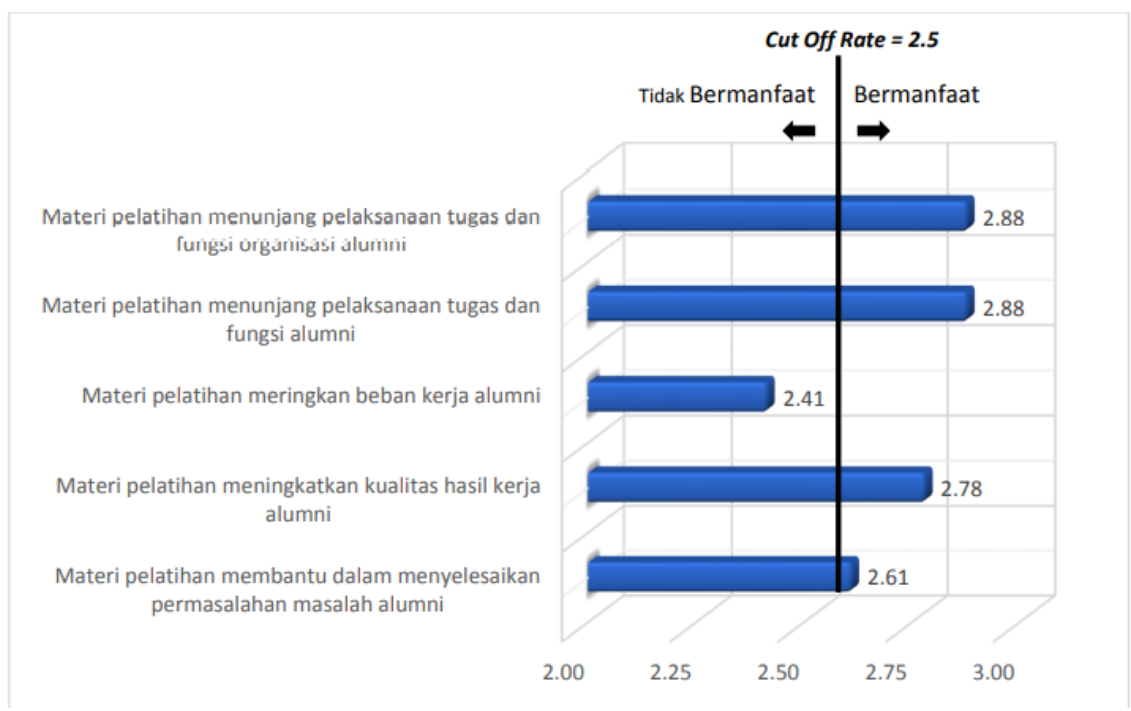

Sumber : Laporan Evaluasi Pasca Diklat PPSDM Aparatur tahun 2019

- diperlukan review kurikulum untuk meningkatkan jenis dan metode pembelajaran , waktu pembelajaran.

- Perlu peningkatan kompetensi widyaiswara.

- Pemanfaatan aplikasi SMILE dalam pembelajaran 
Untuk menunjukan langkah konkret dalam persiapan corporate university, maka data evaluasi diatas perlu didukung dengan analisis strategi SWOT dengan melibatkan pegawai PPSDM Aparatur untuk mengetahui sejauh mana faktor-faktor corprate university dapat dipenuhi.

\section{A. Rumusan Masalah}

Rumusan masalah pada penelitian ini, seberapa siapkah PPSDM Aparatur menuju corporate university 2023, dan langkah-langkah strategi apa yang diperlukan agar tujuan tersebut dapat tercapai.

\section{B. Manfaat}

Penelitian ini diharapkan memberikan manfaat dengan terukurnya kesiapan inovasi corporate university PPSDM A paratur tahun 2023 dengan analisis SWOT.

\section{Metode Penelitian}

Dalam penelitian ini data-data diperoleh dengan menganalisis data sekunder dan data primer yang dianalisis dengan pendekatan kualitatif. Data primer dihasilkan dari kuesioner data analisis SWOT yang dibagikan kepada sejumlah responden di internal PPSDM Aparatur, selain itu data hasil patok banding dengan PLN Corporate University. Adapun data sekunder diperoleh dari hasil evaluasi pelatihan dan studi literatur pada beberapa kajian.

Dalam penelitian ini langkah mendapatkan data dan mengolah data dilaksanakan dengan pendekatan metode kuantitatif dan kualitatif. Jenis data dapat berupa data primer contohnya pada hasil evaluasi pelatihan dan hasil patok banding. Sedangkan untuk data sekunder diperoleh dari literatur - literatur kajian terdahulu tentang corporate university, serta melakukan analisis SWOT untuk menentukan kesiapan PPSDM Aparatur menuju corporate university.

Prosedur analisis SWOT (Rangkuti, 2011), meliputi tahapan sebagai berikut:

1. Menentukan faktor internal dan eksternal yang berpengaruh pada terbentuknya Corporate university, meliputi :

- Faktor internal meliputi kekuatan (strength) yang dimiliki oleh organisasi dari sisi internal yang berpengaruh pada terbentukya corporate university

- Kelemahan (weakness) yang dimiliki organisasi dalam pemenuhan corporate university dari sisi internal

- Oportunity yaitu karakteristik eksternal organisasi yang dijadikan peluang dalam mendukung terbentuknya corporate university

- Threat yaitu karakter eksternal yang memungkinkan dapat menghambat terbentuknya entitas Corporate university

2. Menentukan bobot dari masing-masing komponen data SWOT dengan menyebarkan Kuesioner

3. Menentukan nilai Internal factor analysis strategy (IFAS) dan external factor analysis strategy (EFAS)

4. Menentukan desain strategi dalam kuadran titik perpotongan EFAS dan IFAS 


\section{Tinjauan Pustaka}

Dalam dunia Aparatur Sipil Negara pengembangan sumber daya manusia pada umumnya melalui program pendidikan dan pelatihan. Perubahan arah dari pendidikan dan pelatihan menjadi pengembangan sumber daya manusia perlu dilakukan menuju corporate university (Asman, 2018). Hal ini dilakukan untuk menjawab tantangan ASN dalam menguasai era globalisasi, guna menyusun dan menetapkan kebijakan, serta memberikan pelayanan yang maksimal kepada para pemangku kepentingan baik internal maupun eksternal organisasi

Secara definisi corporate university merupakan salah satu mesin strategis suatu organisasi yang mengintegrasikan sumber daya, proses bisnis, dan orang-orang terlibat dalam proses pembelajaran untuk mencapai performa terbaik dan secara terus menerus meningkatkan knowledge, skill dan attitude dari orang-orang yang berada dalam ekosistem organisasi dengan didukung oleh pengelolaan pengetahuan (knowledge management) (Kementerian Keuangan, 2017). Kegiatan dalam Corpu selaras, sejalan dan terintegrasi dengan program pengelolaan sumber daya manusia (SDM), dengan pengelolaan secara professional melalui learning technology, tentu saja dengan keterlibatan dan dukungan penuh dari pemimpin bisnis tersebut.

Urgensi dari Corpu (Kementerian Keuangan, 2017), secara luas sebagai bentuk adaptasi organisasi terhadap perubahan yang sangat cepat, dengan disertai kondisi-kondisi sebagai berikut :

- Belajar lebih cepat dari ekspektasi pegawai dan organisasi

- Pengembangan SDM harus sejalan dengan rencana strategis

- Proses bisnis pengembangan SDM harus aplikatif, relevan/ adaptif, mudah diakses, dan berdampak tinggi.

- Perkembangan teknologi menyebabkan materi belajar harus mudah diakses kapan saja dan dimana saja

- Kerangka pembelajaran harus mampu mencetak agen perubahan.

- Pengetahuan di organisasi banyak dan beragam, namun tersebar dan melekat pada orang.

Gambar 2. Di bawah ini menunjukan learning focus dari Corpu yang menumbuhkan budaya belajar diperkuat dengan pengelolaan pengetahuan. Dengan haluan visi, misi dan sasaran kinerja organisasi maka seluruh aktifitas performan pegawai dan organisasi mengarah kepada haluan tersebut. Adapun gap dalam pemenuhan performan tersebut dapat diidentifikasi sebagai kebutuhan pembelajaran dengan kerangka pembelajaran 70:20:10 seperti dijelaskan pada gambar di bawah ini, mengedepankan pengalaman pembelajaran terintegrasi di tempat kerja sehingga terbentuk budaya belajar dan penggunaan sistem manajemen pengetahuan. 
Gambar 2. Pembelajaran terintegrasi (sumber : kementerian keuangan, 2017)

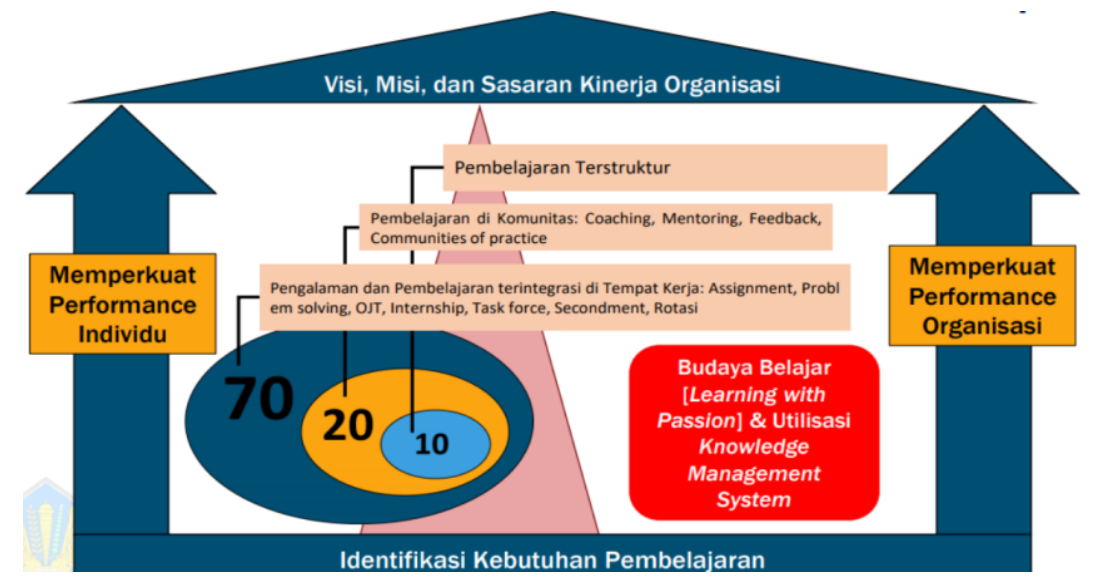

Sumber (Keuangan, 2017) Corporate University. Langkah Mewujudkan Indonesia Corporate University. Selasa, 5 Desember PDF Free Download (docplayer.info)

Dalam pengembangan Corporate university didasarkan pada tujuan-tujuan sebagai berikut (Hearn, 2002 dalam Chusminah, 2015) :

1. Menyelenggarakan pelatihan

2. Memulai dan mendukung perubahan dalam organisasi

3. Mendapatkan hasil maksimal dari investasi dalam pendidikan

4. Membawa budaya umum, loyalitas, dan milik perusahaan

5. Tetap kompetitif dalam perekonomian saat ini

6. Mempertahankan karyawan

Dalam menjalankan tujuan tersebut, corporate university melakukan sejumlah aktifitas dan fungsi sebagai berikut (Allen, 2007 dalam Chusminah, 2015) (Tabel 1):

Tabel 1. Aktivitas dan fungsi Corporate University ( Allen, 2007)

\begin{tabular}{|c|l|c|l|}
\hline No & \multicolumn{1}{|c|}{ Aktifitas dan Fungsi } & No & \multicolumn{1}{|c|}{ Aktifitas dan Fungsi } \\
\hline 1 & Need Assesments & 14 & Managing university partnership \\
\hline 2 & Designing Training Program & 15 & Execorporate university coaching \\
\hline 3 & Delivering Training Program & 16 & Mentoring \\
\hline 4 & $\begin{array}{l}\text { Designing Managerial and } \\
\text { Execorporate university }\end{array}$ & 17 & Career planning \\
\hline 5 & $\begin{array}{l}\text { Delivering Managerial and } \\
\text { Execorporate university }\end{array}$ & 18 & Strategic hiring \\
\hline 6 & Assesing Technology option & 19 & New employee orientation \\
\hline 7 & Delivering e Learning or blended & 20 & Succession planning \\
\hline 8 & Hiring Vendors & 21 & Corporate university change \\
\hline 9 & Managing vendors relationship & 22 & Strategic change \\
\hline 10 & Marketing program internally & 23 & Knowlwdge management \\
\hline 11 & Marketing program externally & 24 & Wisdom management \\
\hline 12 & Evaluating Program & 25 & $\begin{array}{l}\text { Library and electronic collection } \\
\text { of information }\end{array}$ \\
\hline 13 & Evaluating the corporate university & 26 & Research and development \\
\hline
\end{tabular}

Sumber: Chusminah 2015 Jurnal Analisis Implementasi Konsep Corporate University Dalam Meningkatkan Kinerja KaryawanStudi Kasus PT PLN (Persero) Jakarta (researchgate.net) 
Dari berbagai aktivitas tersebut dapat ditunjukan perbedaan yang cukup signifikan antara corporate university dan pelatihan konvensional, sebagai berikut:

Tabel 2. Perbedaan pelatihan koncensional dan corporate university (Chusminah, 2015)

\begin{tabular}{|c|c|c|}
\hline $\begin{array}{c}\text { Divisi Pelatihan dan } \\
\text { pengembangan tradisional }\end{array}$ & Dimensi & Corporate university \\
\hline Kebutuhan operasional & $\begin{array}{l}\text { Pelaksanaan } \\
\text { program }\end{array}$ & Kebutuhan bisnis \\
\hline $\begin{array}{l}\text { Reaktif, orientasi "betulkan } \\
\text { untuk saat ini" }\end{array}$ & $\begin{array}{l}\text { Ketersediaan } \\
\text { program }\end{array}$ & $\begin{array}{l}\text { Proaktif: orientasi } \text { perbaikan, } \\
\text { pembaruan diarahkan ke masa } \\
\text { mendatang }\end{array}$ \\
\hline $\begin{array}{l}\text { Terfragmentasi, program } \\
\text { pembelajaran diadakan sekali } \\
\text { kemudian berhenti }\end{array}$ & $\begin{array}{l}\text { penyampaian } \\
\text { pembelajaran }\end{array}$ & $\begin{array}{l}\text { Proses pembelajaran/pengajaran } \\
\text { berkelanjutan dan terintegrasi }\end{array}$ \\
\hline $\begin{array}{l}\text { Cakupan } \\
\text { pembelajaran dan ragalitas } \\
\text { penyampaian terbatas pada } \\
\text { ruang kelas dan waktu } \\
\text { tertentu }\end{array}$ & $\begin{array}{l}\text { Frekuensi dan } \\
\text { Akses }\end{array}$ & $\begin{array}{l}\text { Virtual, blended learning, dimana } \\
\text { saja, kapan saja, berapa saja, siapa } \\
\text { saja, dan dengan cara apa saja }\end{array}$ \\
\hline Individu, karyawan internal & pengoperasian & Tim komunitas utuh \\
\hline Kompetensi teknis individu & $\begin{array}{l}\text { Focus Kompetensi } \\
\text { yang ditingkatkan }\end{array}$ & Kompetensi organisasi inti \\
\hline $\begin{array}{l}\text { Pelatihan dan pengembangan } \\
\text { dimiliki divisi HR }\end{array}$ & Usulan program & $\begin{array}{l}\text { Pembelajaran / pengajaran dimiliki } \\
\text { unit bisnis }\end{array}$ \\
\hline $\begin{array}{l}\text { untuk mengembangkan atau } \\
\text { meningkatkan keterampilan }\end{array}$ & Dampak & $\begin{array}{l}\text { Meningkatkan kinerja secara } \\
\text { keseluruhan }\end{array}$ \\
\hline $\begin{array}{l}\text { Secara terbuka dengan proses } \\
\text { manual tidak berkaitan dgn } \\
\text { kurikulum pelatihan dan } \\
\text { persyaratan tertentu }\end{array}$ & Registrasi & $\begin{array}{l}\text { Berdasarkan kebutuhan kurikulum } \\
\text { secara online via Learning } \\
\text { Management System (LMS) }\end{array}$ \\
\hline
\end{tabular}

Sumber:Chusminah 2015 Jurnal Analisis Implementasi Konsep Corporate University Dalam Meningkatkan Kinerja Karyawan - Studi Kasus PT PLN (Persero) Jakarta (researchgate.net)

Memahami corporate university yang dijalankan oleh beberapa perusahaan setidaknya meliputi 10 (sepuluh) karakter meliputi :

a) Proaktif mencari dan mengupayakan penyelesaian masalah kinerja melalui solusi pembelajaran (action learning),

b) Kepemilikan program pembelajaran ada di direksi dan tertuang dalam rencana jangka panjang organisasi,

c) Dikelola oleh tenaga professional,

d) Fasilitas pembelajaran terkoneksi secara fisik dan virtual melalui learning management system dan knowledge management system, 
e) Terjalinnya kemitraan dengan akademisi dan lembaga pengembangan pegawai lain,

f) Mendukung program pengembangan individu untuk menunjang karier,

g) Menjadi tempat internalisasi budaya dan tata nilai organisasi,

h) Memiliki program leader as a teacher dan retired faculty,

i) Objek pembelajaran yaitu tenaga kerja yang terlibat dalam bisnis perusahaan, yaitu pegawai, mitra kerja, pelanggan dan masyarakat,

j) Memiliki brand yang kuat untuk meyakinkan stakeholders.

Pola pengembangan corporate university meliputi beberapa komponen penajaman model ADDIE, yang meliputi:

\section{- Analisis Pembelajaran (Learning Analysis)}

Penyelesaian isu-isu bisnis yang semakin kompleks pada perusahaan-perusahaan dapat dijawab dengan peningkatan kapabilitas yang dipenuhi melalui program pembelajaran yang selaras dengan strategi organisasi. Analisis kebutuhan pembelajaran (Learning need analysis) yang tepat, mampu menghadapi tantangan bisnisnya.

Kunci tahapan ini dengan mengidentifikasi kebutuhan pembelajaran yang diperoleh dari perbedaan antara kinerja aktual (actual performance) dan kinerja yang diharapkan (expected performance). Dengan informasi ini maka diketahui faktor apa saja yang perlu ditingkatkan dalam penyelesaian visi dan misi organisasi tersebut, baik jenis pembelajaran maupun objek (pembelajarnya)

Komponen analisis kebutuhan pembelajaran terdiri dari 3 hal, yaitu: analisis kompetensi inti (core compentency analysis), analisis kebutuhan pengembangan (development need analysis) dan analisis kebutuhan pelatihan (training need analysis). Analisis Kompetensi Inti menginformasikan kompetensi inti apa saja yang diperlukan untuk menunjang kinerja bisnis perusahaan. Analisis Kompetensi Inti ini dijabarkan dari visi dan misi organisasi.

Berikutnya, Analisis Kebutuhan Pengembangan (DNA) merupakan kegiatan yang didorong untuk pemenuhan kebutuhan organisasi. Langkah-langkah yang dilakukan pada tahapan tersebut, yaitu:

a. Mengukur kesenjangan posisi perusahaan saat ini dan yang akan datang.

b. Mengidentifikasi hambatan yang ditemukan dalam menempuh jalan menuju cita-cita.

c. Mengembangkan rencana untuk menutup kesenjangan.

Tahapan berikutnya yaitu Analisis Kebutuhan Pelatihan (TNA) berupa serangkaian kegiatan untuk menganalisis kebutuhan pelatihan yang sesuai dengan Analisis Kebutuhan Pengembangan dan Analisis Kompetensi Inti.

Contoh PLN melaksanakan Pembelajaran Berbasis Kinerja (PBK). Terdapat 3 tahapan, diantaranya Penemuan fakta (fact finding), Penyelesaian Penyebab Akar Permasalahn (Root Cause Problem Solving) (RCPS) dan Kesiapan Survey (Survey Readiness). PLN Corpu mencari data kinerja yang akan ditingkatkan performanya, Ialu ditemu kenali akar permasalahannya, 
serta menentukan langkah yang tepat dalam penyelesaian (learning solution). Tahap terakhir yaitu melakukan kesiapan survey untuk mengetahui kesiapan SDM untuk melaksanakan solusi permasalahan tersebut.

\section{- Disain Pembelajaran (Learning Design)}

Kapabilitas SDM organisasi ini ditantang dapat menyesuaikan di era VUCA ini, sehingga organisasi tetap bisa eksis ditengah perubahan. Kesuksesan tersebut dipengaruhi oleh perspektif pembelajaran dan pertumbuhan melalui desain yang tepat (Kaplan, 1996 dalam Satrijono 2017).

Aspek-aspek yang penting dalam disain pembelajaran, adalah sebagai berikut :

a. Kurikulum, Silabus, Materi Pembelajaran

Dalam menyusun materi agar selalu up to date, PLN melakukan beberapa cara, diantaranya (1) mendidik para ahli internal, serta bekerjasama dengan para pakar dibidang tertentu (subject matter expert) dari luar organisasi. (2) bekerjasama dengan lembaga pelatihan lain sebagai pengajar eksternal (3) mengikuti sertifikasi untuk memutakhirkan keahlian di bidang pembelajaran.

b. Desain Metode Pembelajaran

Dalam mendesain metode pembelajaran, salah satunya dengan mengembangakan dari setiap modul seperti bentuk kelas (classroom), pembelajaran elektronik ( $e$ learning), penetapan dan mekanisme pembinaan (assignment and mechanism of coaching). Hal ini disesuaikan dengan tujuan pembelajarannnya. Berbeda dengan Telkom, menyusun Integrated Learning Cycle, mulai dari self-learning, e-learning, classroom, penugasan berupa pembelajaran aksi (action learning), Pembelajaran dengan yang lain (learning with others) dan terakhir berbagi pengetahuan (knowledge sharing).

c. Desain Kompetensi Instruktur

Beberapa metode dalam menetapkan instruktur pada umumnya dibagi ke dalam 3 jenis, yaitu: instruktur tetap, instruktur tidak tetap dan instruktur pensiunan. Pemilihan instruktur tergantung pada materi yang dibutuhkan, misal untuk kepemimpinan PT. Semen Indonesia memilih dari luar organisasi untuk membuka wawasan global, sementara untuk materi teknis, didominasi oleh instruktur internal.

d. Desain Perangkat dan Teknologi Pembelajaran

Perangkat pembelajaran sudah berkembang maju, dikenal dengan sistem manajemen pembelajaran (learning management system), saat ini pendekatan baru menggunakan teknologi big data analysis (mengenai data personal karyawan, kompetensi, dll), dengan memanfaatkan sejumlah data yang terakumulasi untuk digunakan dalam perencanaan program.

Desain pembelajaran yang diterapkan oleh Pertamina memiliki 6 langkah, diantaranya:

(1) Pengumpulan kebutuhan pembelajaran (Gather learning needs), yaitu: mengidentifikasi kebutuhan organisasi, menentukan kompetensi yang dibutuhkan dalam mencapai visi dan misi organisasi.

(2) Menetapkan kebutuhan kursus (Establish course requirement): menentukan target pembelajar dan prasyarat peserta 
(3) Merancang kerangka kursus (Design course framework): menentukan modul, metode pembelajaran, dan penganggarannya

(4) Pengembangan konten kursus (Develop course contents): Penyelesaian desain kursus, perlengkapan pelatihan dan pengukuran evaluasi

(5) Pengujian dan kursus percontohan Test and pilot course: mengadakan proyek percontohan (pilot project) dan melaksanakan evaluasi

(6) Melaksanakan dan memelihara pelaksanaan kursus (Release and maintain course): integrasi dengan sistem $\mathrm{HR}$, dan pemutakhiran pelatihan sesuai dengan hasil evaluasi.

\section{- Penyampaian Pembelajaran (Learning delivery)}

Penyampaian pembelajaran adalah proses perencanaan serta pelaksanaan pendidikan dan pelatihan mulai dari penjadwalan, penyusunan anggaran, fasilitas dan laboratorium, sumber daya hingga instruktur, yang dilakukan didalam kelas sampai sertifikasi pembelajaran. Penyampaian pembelajaran meliputi dua metode yaitu konvensional di dalam kelas dan pembelajaran digital secara jarak jauk. Proses penyampaian pembelajaran yang terdapat pada Corporate University diperlukan struktur pembelajaran yang sistematis dengan instruktur yang berkualitas dan perangkat pembelajaran yang memadai. Penyampaian pembelajaran yang terjadi di PLN Corpu meliputi empat tahapan, yaitu : persiapan, pelaksanaan, pasca pelaksanaan dan pelaporan pembelajaran. Efisiensi anggaran membawa pelaksanaan pembelajaran lebih efektif, strategi yang diterapkan diantaranya melalui pembelajaran digital dan blended learning. Kunci keberhasilan Penyampaian Pembelajaran yaitu:

- Instruktur ahli di bidangnya

- Materi selalu diperbaharui

- Materi mengacu pada tren bisnis dan strategi perusahaan

- Dilakukan assessment pada setiap materi yang disampaikan

- Metoda pengajaran bersifat aktif dan partisipatif

- Ketersediaan ruang dan perangkat pembelajaran yang baik

- Penyampaian dengan Bahasa sederhana agar dapat dimengerti.

\section{- Learning evaluasi}

Proses evaluasi yang sering kita lakukan yaitu dengan menggunakan model Kirk Patrik, mulai dari tahapan reaksi, pembelajaran, perubahan perilaku dan hasil. Proses evaluasi yang ingin dilakukan pada setiap pelatihan, di desain sejak mulai tahap desain pembelajaran. 


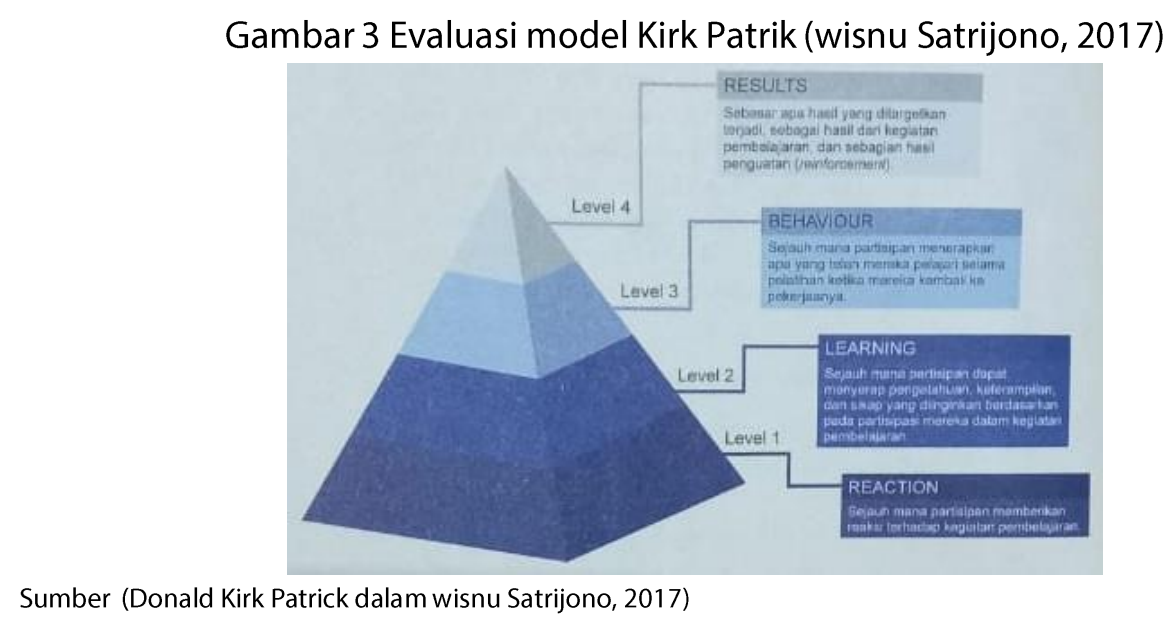

Pada PT.PLN Corpu dapat ditunjukan hasil evaluasi sebagai berikut :

- Evaluasi Level I pengukuran kepuasan terhadap materi pembelajaran, instruktur, fasilitas, dll

- Evaluasi Level II pengukuran peningkatan pengetahuan dan keterampilan karyawan setelah pembelajaran dengan melakukan teat awal (pre test) dan test akhir (post test)

- Evaluasi Level III pengukuran terhadap perubahan perilaku, dengan cara melakukan survei kepada atasannya setelah selesai pelatihan tiga bulan.

- Evaluasi Level IV pengukuran terhadap kinerja karyawan baik proses maupun hasilnya

- Evaluasi Level V pengukuran return of training investment (ROTI) berupa tingkat pengembalian investasi terhadap benefit dan cost dalam program pelatihan

Simplicity is the key menjadi arah evaluasi pembelajaran di Unilever Corpu namun powerfull, dengan lingkup pertanyaan menilai pelatihan, menilai fasilitator, menilai isi pelatihan dan relevansinya dengan pekerjaan. Penilaian pembelajaran Corpu tidak sebatas pada lulus atau tidak lulus, namun bagaimana menerjemahkan hasil training ke dalam performance management.

Gambar 4. Pembelajaran berdasarkan kinerja, PLN, 2020

\section{PERFORMANCE BASED LEARNING}

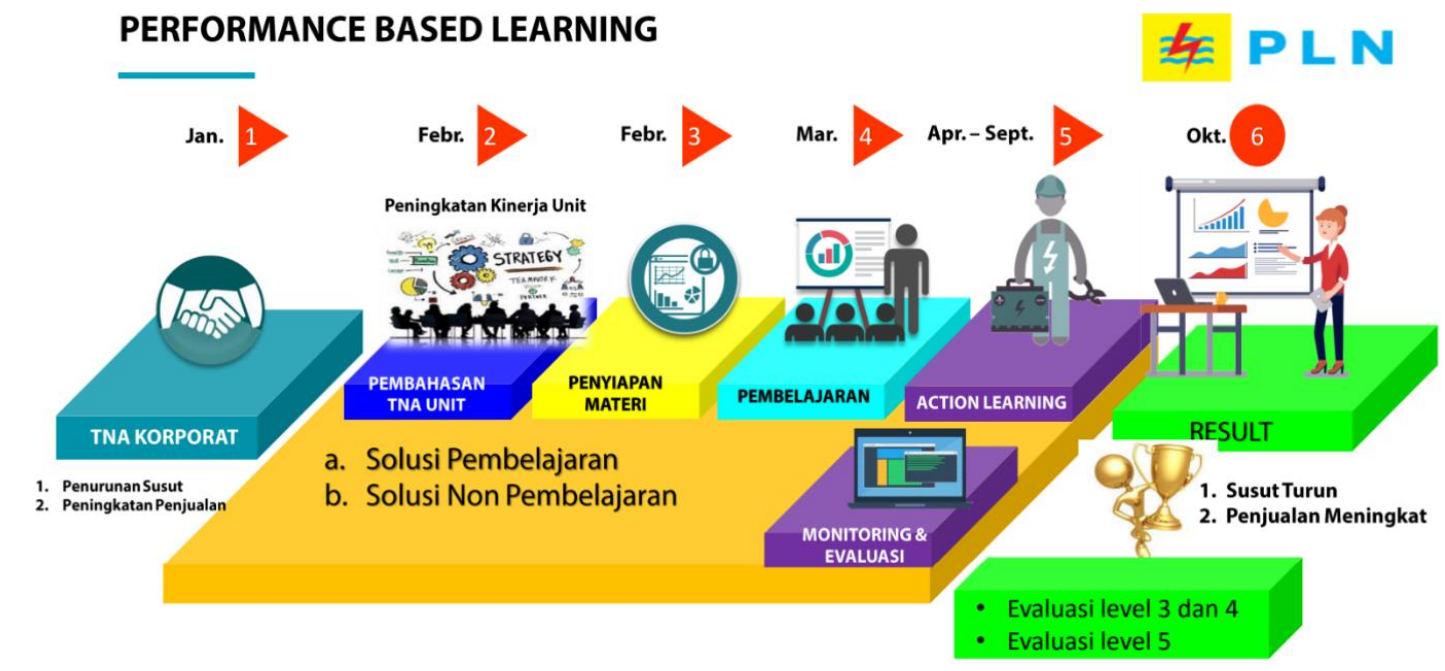


Kolo, 2013 mengungkapkan dalam training value chain corporate university bahwa $75 \%$ waktu dibutuhkan untuk pengembangan program dan program penyampaian.

\section{- Pembelajaran Dijital (Digital Learning)}

Fenomena penggunaan digital learning, sudah diterapkan di PPSDM Aparatur dengan platform e learning SMILE. Hal ini dilandasi dengan kebutuhan pembelajaran jarak jauh yang dapat memangkas anggaran, dan menunjang aktivitas peserta terlebih dimasa pandemik seperti saat ini. Pemanfaatan dpembelajaran dijital yang terintergrasi dalam system manajemen pembelajaran. Jenis - jenis pembelajaran dijital meliputi pemanfaatan buku elektronik, pembelajaran melalui video, tampilan cepat (rapid slide), tampilan interakti (interactive slide), dan evaluasi. Pembelajaran di beberapa perusahaan dikembangkan dalam bentuk permainan permainan dan simulasi. Hasil pembelajaran dapat diukur melalui Pengukuran hasil pembelajaran (Learning Impact MeasurementLIM)) level 1 dan 2 dengan metode evaluasi mandiri (self-evaluation).

\section{- Pembelajaran Kepemimpinan (Leadership Learning)}

Perubahan eksternal dan kekuatan daya saing menuntut organisasi mampu untuk beradaptasi, hal ini menjadikan sumber pengetahuan yang mampu meningkatkan kemampuan SDM untuk mengembangkan dan menerapkan perbaikan dalam organisasi. Dalam situasi inilah dituntut pemimpin yang mampu menciptakan lingkungan yang memungkinkan SDM meningkatkan pengetahuan dan bertindak untuk mengambil keputusan yang tepat. Pemimpin juga berperan sebagai pengajar yang membagikan keterampilan dan pengerahuan kepada karyawannya. Sehingga hal ini menjadikan pemimpin dalam corpu sebagai pusat pengetahuan.

Dari semua lini komponen-komponen Corporate University, PLN menyatakan bahwa peranan pimpinan sangat besar pada gambar 4 pada point TNA Corporate dan pembahasan TNA unit, berdasarkan hasil diskusi dengan Tim PLN Corpu, keterbukaan dalam menunjukan pencapaian kinerjanya, hal ini akan menjadi landasan bentuk pembelajaran yang dibutuhkan. Hal ini didukung dengan pembahasan unit melibatkan pemimpin-pemimpin unit.

Gambar 5 Pelaksanaan Benchmark PPSDM Aparatur ke PLN Corpu dihadiri General Manager Chief Learning Officer PLN Corpu beserta Jajarannya, Mei 2020

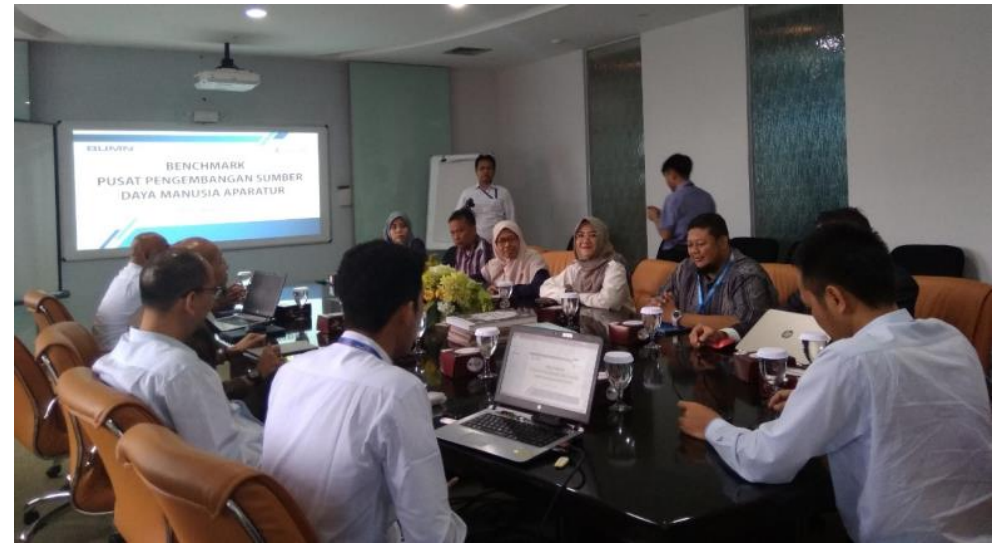

Sumber: Hasil patok banding PPSDMA dan PLN 


\section{- Analisis SWOT}

SWOT Salah satu alat manajemen, yang dipergunakan dalam suatu perencanaan strategis unttuk mengevaluasi faktor-faktor yang berpengaruh dalam pencapaian tujuan. Faktorfaktor tersebut dapat dari lingkungan internal (kekuatan dan kelemahan) serta dari eksternal (peluang dan ancaman). Dengan SWOT dapat digambarkan kondisi saat ini.

Peninjauan faktor-faktor yang dievaluasi pada analisis SWOT meliputi kekuatan, kelemahan, peluang dan ancaman (Rangkuti, 2011 dalam Hendris 2018). (Gambar 3).

Gambar 6. Peta hasil analisis EFAS dan IFAS (Rangkuti, 2011)

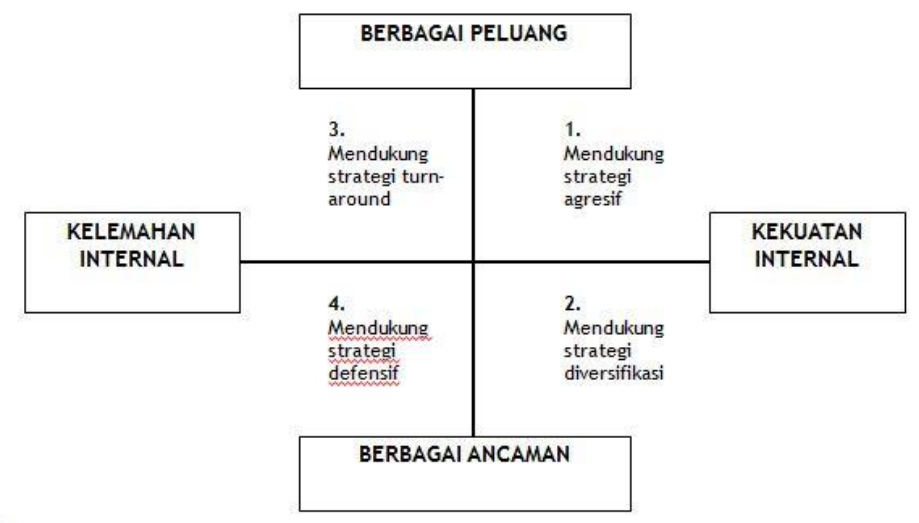

(Sumber : Freddy Rangkuti, 2011)

- Kekuatan, yaitu menunjukan variable-variabel kelebihan yang dimiliki oleh suatu organisasi secara internal

- Kelemahan, yaitu menunjukan variable-variabel kelemahan yang dimiliki organisasi

- Peluang, yaitu kondisi eksternal yang dapat dijadikan peluang keuntungan.

- Ancaman, yaitu karakteristik eksternal, yang dapat menghambat pencapaian strategi organisasi.

Pengolahan data keempat faktor tersebut dapat menunjukan posisi sebagai suatu saran tindakan seperti di uraikan di bawah:

- Kuadran I

- Merupakan situasi sangat menguntungkan

- Perusahaan memiliki peluang dan kekuatan, dapat memanfaatkan peluang yang ada.

- Strategi yang diterapkan, mendukung kebijakan pertumbuhan agresif (growthoriented strategy)

- Kuadran II

- Meskipun memiliki berbagai ancaman, perusahaan masih memiliki kekuatan dari segi internal

- Strategi yg diterapkan: menggunakan kekuatan untuk memanfaatkan peluang jangka panjang dengan cara strategi diversifikasi (produk/pasar)

- Kuadran III 
- Perusahaan menghadapi peluang pasar yang sangat besar, tetapi di lain pihak menghadapi beberapa kendala/kelemahan internal

- Strategi yang diterapkan:meminimalkan masalah-masalah internal perusahaan, sehingga dapat merebut peluang pasar.

- Kuadran IV

- Situasi yg tdk menguntungkan, perusahaan menghadapi berbagai ancaman dan kelemahan internal

\section{Pembahasan}

\section{Hasil analisis SWOT}

Dalam menentukan parameter-parameter data analisis SWOT, penulis mengacu pada pengembangan model ADDIE pada lembaga corporate university yaitu analisis pembelajaran, desain pembelajaran, penyampaian pembelajaran, evaluasi pembelajaran, dilengkapi dengan pembelajaran dijital dan kepemimpinan. Analisis parameter tersebut dikemas dalam lembar kuesioner kepada pegawai PPSDM Aparatur, untuk turut menilai sejauh mana kesesuaian kondisi eksisting PPSDM APARATUR dengan pemenuhan kebutuhan pelaksanaan ASN Corporate University.

Nilai EFAS dan IFAS tersebut, dipergunakan untuk menentukan grand strategy yang perlu diambil dalam pemenuhan tujuan organisasi dalam hal ini penerapan ASN Corporate university

Titik pertemuan antara EFAS dan IFAS ada pada kuadran I, yaitu situasi sangat menguntungkan karena organisasi mampu memanfaatkan peluang, sehingga mendukung kebijakan pertumbuhan agresif (Gambar 4). Data ini perlu di klarifikasi dengan hasil Evaluasi Paska Diklat kegiatan pelatihan di PPSDM Aparatur, penulis membandingkan dengan data tahun 2019, hal ini dilakukan untuk melihat dampak pelatihan yang diselenggarakan PPSDM Aparatur (Tabel 4). Diklat yang disasar pada kegiatan evaluasi tersebut meliputi pelatihan dasar CPNS, Kegiatan pelatihan Teknis Dasar TK. I, dan pendidikan kepemimpinan tingkat III keseluruhannya dilaksanakan tahun 2018.

Tabel 3. SWOT ASN Corporate University

\begin{tabular}{|c|c|c|c|c|c|}
\hline \multirow{2}{*}{ No } & \multirow{2}{*}{ Pertanyaan } & \multicolumn{4}{|c|}{ Nilai } \\
\hline & & Signifikan & Bobot & Rating & Skor \\
\hline \multicolumn{6}{|c|}{ Faktor Internal Strength (kekuatan) } \\
\hline 1 & $\begin{array}{l}\text { Pemimpin menjadi katalisasi pembelajaran, } \\
\text { mendorong dan memastikan adanya mekanisme } \\
\text { transfer pembelajaran }\end{array}$ & 3 & 0,16 & 3 & 0,47 \\
\hline 2 & Materi yang disampaikan selalu diperbaharui & 2 & 0,11 & 3 & 0,32 \\
\hline 3 & Materi mengacu pada tren dan strategi organisasi & 2 & 0,11 & 4 & 0,42 \\
\hline 4 & Dilakukan pretest dan posttest pelatihan & 1 & 0,05 & 3 & 0,16 \\
\hline 5 & Metoda pengajaran bersifat aktif dan partisipatif & 2 & 0,11 & 3 & 0,32 \\
\hline 6 & $\begin{array}{l}\text { Ketersediaan ruang dan perangkat pembelajaran } \\
\text { yang baik }\end{array}$ & 1 & 0,05 & 3 & 0,16 \\
\hline 7 & Penyampaian dengan bahasa yang sederhana & 2 & 0,11 & 3 & 0,32 \\
\hline 8 & Terdapat Pengembangan pembelajaran dijital, baik & 3 & 0,16 & 4 & 0,63 \\
\hline
\end{tabular}




\begin{tabular}{|c|c|c|c|c|c|}
\hline & self-learning maupun blanded learning & & & & \\
\hline 9 & $\begin{array}{l}\text { Pemateri pada pelatihan merupakan ahli di } \\
\text { bidangnya }\end{array}$ & 3 & 0,16 & 4 & 0,63 \\
\hline & Jumlah & 19 & 1 & & 3.42 \\
\hline \multicolumn{6}{|c|}{ Faktor Internal Weakness (kelemahan) } \\
\hline 1 & $\begin{array}{l}\text { program pelatihan memperhatikan visi dan misi } \\
\text { organisasi }\end{array}$ & 3 & 0,13 & 2 & 0,26 \\
\hline 2 & $\begin{array}{l}\text { Program pelatihan memahami isu-isu strategis } \\
\text { organisasi }\end{array}$ & 3 & 0,13 & 2,5 & 0,33 \\
\hline 3 & $\begin{array}{l}\text { Analisis kebutuhan diklat memanfaatkan data } \\
\text { epegawaian (penilaian kinerja, dan perencanaan } \\
\text { karir pegawai) }\end{array}$ & 2 & 0,09 & 2,5 & 0,22 \\
\hline 4 & $\begin{array}{l}\text { Analisis kebutuhan diklat menggunakan metoda } \\
\text { dan teknis analisis tertentu (observasi, kuesioner, } \\
\text { wawancara, FGD dan assessment) }\end{array}$ & 2 & 0,09 & 1,5 & 0,13 \\
\hline 5 & Desain pembelajaran sesuai hasil TNA & 3 & 0,13 & 2,5 & 0,33 \\
\hline 6 & $\begin{array}{l}\text { Desain pembelajaran melibatkan unit-unit } \\
\text { organisasi }\end{array}$ & 2 & 0,09 & 2 & 0,17 \\
\hline 7 & $\begin{array}{l}\text { Desain pembelajaran melibatkan subject matter } \\
\text { expert (internal dan eksternal organisasi) }\end{array}$ & 3 & 0,13 & 1,5 & 0,2 \\
\hline 8 & $\begin{array}{l}\text { Tergambar jelas dampak pembelajaran pelatihan } \\
\text { dan pengukurannya }\end{array}$ & 3 & 0,13 & 2 & 0,26 \\
\hline 9 & $\begin{array}{l}\text { Menyiapkan pilot program pelatihan (implementasi } \\
\text { skala kecil) }\end{array}$ & 2 & 0,09 & 2 & 0,17 \\
\hline & $\begin{array}{ll} & \text { Jumlah }\end{array}$ & 23 & 1 & & 2,07 \\
\hline \multicolumn{6}{|c|}{ Faktor Eksternal Opportunities (peluang) } \\
\hline 1 & Profilling karyawan & 2 & 0,13 & 3,5 & 0,44 \\
\hline 2 & $\begin{array}{l}\text { Terdapat peta kompetensi inti yang dibutuhkan } \\
\text { organisasi }\end{array}$ & 3 & 0,19 & 3 & 0,56 \\
\hline 3 & $\begin{array}{l}\text { Terdapat peta kebutuhan pengembangan } \\
\text { organisasi dan pegawai }\end{array}$ & 2 & 0,13 & 4 & 0,5 \\
\hline 4 & $\begin{array}{l}\text { Terdapat potret tingkat penguasaan kompetensi } \\
\text { dan kesenjangannya }\end{array}$ & 3 & 0,19 & 3,5 & 0,66 \\
\hline 5 & Melakukan monitoring kinerja pegawai & 3 & 0,19 & 4 & 0,75 \\
\hline 6 & Meninjau kontrak kinerja (tiap semester) & 3 & 0,19 & 3,5 & 0,66 \\
\hline & & 16 & 1 & & 2,81 \\
\hline \multicolumn{6}{|c|}{ Faktor Eksternal Threat (ancaman) } \\
\hline 1 & $\begin{array}{l}\text { Semakin berkembang organisasi serupa pada saat } \\
\text { ini }\end{array}$ & 1 & 0,13 & 2,9 & 0,36 \\
\hline 2 & $\begin{array}{l}\text { Terbatasnya data kepegawaian (kompetensi dan } \\
\text { kinerja) yang diperlukan dalam pengembangan } \\
\text { program pelatihan }\end{array}$ & 2 & 0,25 & 2 & 0,5 \\
\hline 3 & $\begin{array}{l}\text { Evaluasi dampak pembelajaran pada pelatihan } \\
\text { tidak dilakukan secara optimal }\end{array}$ & 2 & 0,25 & 2,5 & 0,63 \\
\hline 4 & $\begin{array}{l}\text { Para Pemangku kebijakan dilingkungan KESDM } \\
\text { terlibat dalam penentuan kebutuhan pembelajaran } \\
\text { organisasi dan pegawai }\end{array}$ & 3 & 0,38 & 1 & 0,38 \\
\hline & & 8 & 1 & & 1,86 \\
\hline
\end{tabular}


Dari data di atas maka dapat diketahui nilai Internal factor analysis strategy (IFAS) dan External Factor analysis Strategy ( EFAS ). Nilai IFAS yaitu (3.42-2.07) 1.35 sedangkan nilai EFAS yaitu (3.56 - 1.86) 1.7 (Gambar 5).

Gambar 7. plotting hasil EFAS dan IFAS berdasarkan hasil analisis SWOT

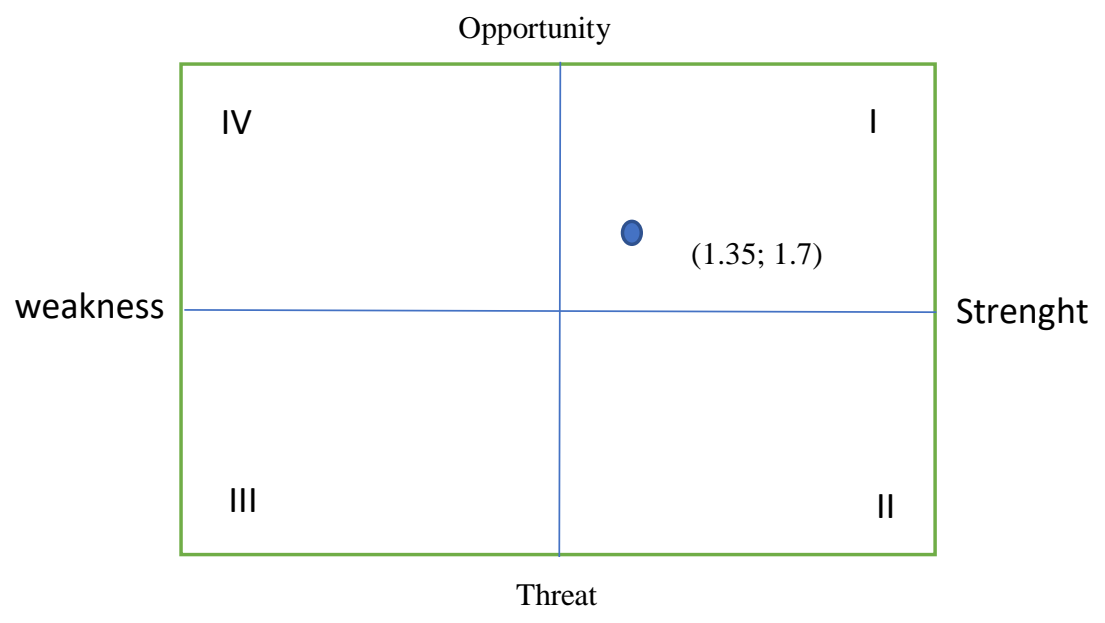

Sumber PPSDM Aparatur hasil kuesioner SWOT Corporate University

Tabel 4. Deskripsi faktor internal dengan hasil Evaluasi Paska Diklat 2019

\begin{tabular}{|c|c|c|}
\hline No & Faktor Internal & Hasil Evaluasi Pasca Diklat Tahun 2019 \\
\hline \multicolumn{3}{|c|}{ Strength (kekuatan) } \\
\hline 1 & $\begin{array}{l}\text { nimpin menjadi katalisasi } \\
\text { nbelajaran, mendorong dan } \\
\text { mastikan adanya mekanisme transfer } \\
\text { nbelajaran }\end{array}$ & \multirow{11}{*}{$\begin{array}{l}\text { - Pada faktor internal ini, catatan dari } \\
\text { peserta Diklat Teknis Dasar tingkat I, } \\
\text { menunjukan perlunya kajian kembali } \\
\text { kurikulum diklat, pemanggilan peserta } \\
\text { disesuaikan dengan Permen yang } \\
\text { berlaku, peningkatan kualitas } \\
\text { widyaiswara dan metoda } \\
\text { pembelajarannya, keterlibatan expert } \\
\text { dalam pengajaran, materi lebih up to } \\
\text { date, perangkat modul dilengkapi, dan } \\
\text { pemanfaatan pembelajaran dijital. } \\
\text { Penerapan materi hasil pembelajaran } \\
\text { minim pada Pendidikan } \\
\text { - Sedangkan panjukn } \\
\text { Kepemimpinan tingkat III menunjukan } \\
\text { perlunya peningkatan kompetensi } \\
\text { pengajar dan narasumber, serta lingkup } \\
\text { pembelajaran yang terpaku pada } \\
\text { penyusunan proyek perubahan, } \\
\text { beberapa proper kurang implementatif } \\
\text { karena legacy alumni terhadap } \\
\text { kebijakan mandatori, diperlukan materi } \\
\text { terkait tugas kepemimpinan }\end{array}$} \\
\hline 2 & & \\
\hline 3 & & \\
\hline 4 & & \\
\hline 5 & & \\
\hline 6 & & \\
\hline 7 & & \\
\hline 8 & & \\
\hline 9 & & \\
\hline \multicolumn{2}{|c|}{ Weakness (kelemahan) } & \\
\hline 1 & & \\
\hline
\end{tabular}




\begin{tabular}{|c|c|c|}
\hline 2 & $\begin{array}{l}\text { Program pelatihan memahami isu-isu } \\
\text { strategis organisasi }\end{array}$ & \multirow{8}{*}{$\begin{array}{l}\text { diantaranya pengambilan keputusan, } \\
\text { hasil positif dapat meningkatkan kinerja } \\
\text { lebih efektif dan efisien, serta } \\
\text { mendukung perubahan perilaku ke } \\
\text { arah lebih baik } \\
\text { - Dalam pelatihan dasar diperlukan } \\
\text { sinergitas antara biro SDM dengan } \\
\text { PPSDM Aparatur, diperlukan kegiatan } \\
\text { lanjutan setelah Pelatihan dasar seperti } \\
\text { Teknis Dasar I dan magang, komunikasi } \\
\text { dibangun dengan mentor selama } \\
\text { pelaksanaan Pelatihan Dasar (latsar) } \\
\text { untuk mendukung pelaksanaan } \\
\text { aktualisasi, hasil pelatihan terdapat } \\
\text { perubahan perilaku kearah lebih baik } \\
\text { dan terdapat peningkatan kinerja }\end{array}$} \\
\hline 3 & $\begin{array}{l}\text { Analisis kebutuhan diklat memanfaatkan } \\
\text { data kepegawaian (penilaian kinerja, dan } \\
\text { perencanaan karir pegawai) }\end{array}$ & \\
\hline 4 & $\begin{array}{l}\text { Analisis kebutuhan diklat menggunakan } \\
\text { metoda dan teknis analisis tertentu } \\
\text { (observasi, kuesioner, wawancara, FGD } \\
\text { dan assessment) }\end{array}$ & \\
\hline 5 & Desain pembelajaran sesuai hasil TNA & \\
\hline 6 & $\begin{array}{l}\text { Desain pembelajaran melibatkan unit- } \\
\text { unit organisasi }\end{array}$ & \\
\hline 7 & $\begin{array}{l}\text { Desain pembelajaran melibatkan subject } \\
\text { matter expert (internal dan eksternal } \\
\text { organisasi) }\end{array}$ & \\
\hline 8 & $\begin{array}{l}\text { Tergambar jelas dampak pembelajaran } \\
\text { pelatihan dan pengukurannya }\end{array}$ & \\
\hline 9 & $\begin{array}{l}\text { Menyiapkan pilot program pelatihan } \\
\text { (implementasi skala kecil) }\end{array}$ & \\
\hline
\end{tabular}

Dari data faktor internal di atas, serta keterkaitannya dengan hasil Evaluasi Paska Diklatmenunjukan adanya perbaikan yang perlu dilakukan, agar memudahkan pencapaian menuju PPSDM Aparatur Corporate university (Tabel 5).

Tabel 5. Identifikasi faktor eksternal versus hasil evaluasi pasca diklat 2019

\begin{tabular}{|c|c|c|}
\hline No & Faktor Eksternal & $\begin{array}{l}\text { Hasil Evaluasi Pasca Diklat Tahun } \\
2019\end{array}$ \\
\hline \multicolumn{2}{|c|}{ Opportunities (peluang) } & \multirow{11}{*}{$\begin{array}{l}\text { - Pada diklat kepemimpinan } \\
\text { terdapat beberapa saran } \\
\text { diantaranya implementasi proyek } \\
\text { perubahan kurang implementatif } \\
\text { dikarenakan peta jabatan unit } \\
\text { berubah-ubah, terdapat } \\
\text { peningkatan kinerja setelah } \\
\text { mengikuti pelatihan, } \\
\text { Pada pelatihan Teknis Dasar } \\
\text { Tingkat l, kepesertaan diklat } \\
\text { dipanggil kurang sesuai dengan } \\
\text { Permen terkait Teknis Dasar, hasil } \\
\text { diklat tidak berpengaruh pada } \\
\text { penilaian atasan maupun rekan } \\
\text { kerja, terdapat perbedaan } \\
\text { ekspektasi kegiatan pelatihan } \\
\text { Teknis pelaksana baik peserta }\end{array}$} \\
\hline 1 & Profil karyawan & \\
\hline 2 & $\begin{array}{l}\text { Terdapat peta kompetensi inti yang } \\
\text { dibutuhkan organisasi }\end{array}$ & \\
\hline 3 & $\begin{array}{l}\text { Terdapat peta kebutuhan pengembangan } \\
\text { organisasi dan pegawai }\end{array}$ & \\
\hline 4 & $\begin{array}{l}\text { Terdapat potret tingkat penguasaan } \\
\text { kompetensi dan kesenjangannya }\end{array}$ & \\
\hline 5 & Melakukan monitoring kinerja pegawai & \\
\hline 6 & Meninjau kontrak kinerja (tiap semester) & \\
\hline \multicolumn{2}{|r|}{ Threat (ancaman) } & \\
\hline 1 & $\begin{array}{l}\text { Semakin berkembang organisasi serupa } \\
\text { pada saat ini }\end{array}$ & \\
\hline 2 & $\begin{array}{l}\text { Terbatasnya data kepegawaian (kompetensi } \\
\text { dan kinerja) yang diperlukan dalam } \\
\text { pengembangan program pelatihan }\end{array}$ & \\
\hline 3 & $\begin{array}{l}\text { Evaluasi dampak pembelajaran pada } \\
\text { pelatihan tidak dilakukan secara optimal }\end{array}$ & \\
\hline
\end{tabular}




\begin{tabular}{|c|l|l|}
\hline 4 & $\begin{array}{l}\text { Para Pemangku kebijakan dilingkungan } \\
\text { KESDM terlibat dalam penentuan kebutuhan } \\
\text { pembelajaran organisasi dan pegawai }\end{array}$ & $\begin{array}{l}\text { maupun atasan. Pelatihan } \\
\text { terintegrasi dengan program } \\
\text { pengembangan pegawai }\end{array}$ \\
\hline \multicolumn{2}{|l|}{ Sumber PPSDM Aparatur hasil kuesioner SWOT Corporate University }
\end{tabular}

Pada faktor eksternal diperlukan peningkatan komunikasi dengan pihak stakeholder, sehingga perangkat yang dibutuhkan menuju PPSDM Aparatur, yang dirasakan pula menjadi faktor yang perlu diperbaiki seperti pada hasil evaluasi diklat berupa perubahan peta jabatan, serta para pemangku kebijakan dilibatkan dalam penentuan program sehingga hasil diklat dapat dirasakan dan meningkatkan kompetensi peserta diklat dalam profil pegawai.

\section{Rancangan Model Corporate university}

Dalam mengadopsi potret Corpu di beberapa organisasi diatas, maka Penulis menyusun model rancangan corporate university PPSDM Aparatur beserta road mapnya, hal ini didasarkan pada pengembangan model ADDIE pada Corporate university yang dihasilkan melalui analisis SWOT dan hasil evaluasi pasca diklat (Gambar 6).

Seluruh aktivitas corporate university dikendalikan oleh manajer Lini pada organisasi tersebut, hal ini seperti disampaikan oleh Kepala PLN Corpu pada saat patok banding. Hal ini menjadikan keterlibatan pucuk pimpinan cukup besar (Gambar 6) dalam menentukan program pengembangan sumber daya manusia, karena dilakukan cukup intensif dengan data-data kompetensi eksisting disertai hasil wawancara pencapaian kinerja masing-masing unit. Sehingga entitas corpu mendapatkan data yang cukup akurat dan penyelenggaraan pelatihan pun berbasis performance management.

Keterlibatan pimpinan dalam penyusunan road map ppsdm aparatur dapat ditunjukan internalisasi entitas Corpu pada tahun 2021, dan dilanjutkan dengan penyusunan pedoman pengembangan SDM berbasis Corpu yang menyeluruh oleh seluruh stakeholder PPSDM Aparatur. 
Gambar 8 Model Rancangan dan Road map Corporate university PPSDM Aparatur

\section{PPSDM APARATUR}

KEMENTERIAN ENERGIDAN

SUMBER D.A YA MINERAL

\section{CORPORATE UNIVERSITY TO BE}

Rancangan model lembaga Corporate university PPSDM Aparatur, berdasarkan komponen-komponen pendukungnya,

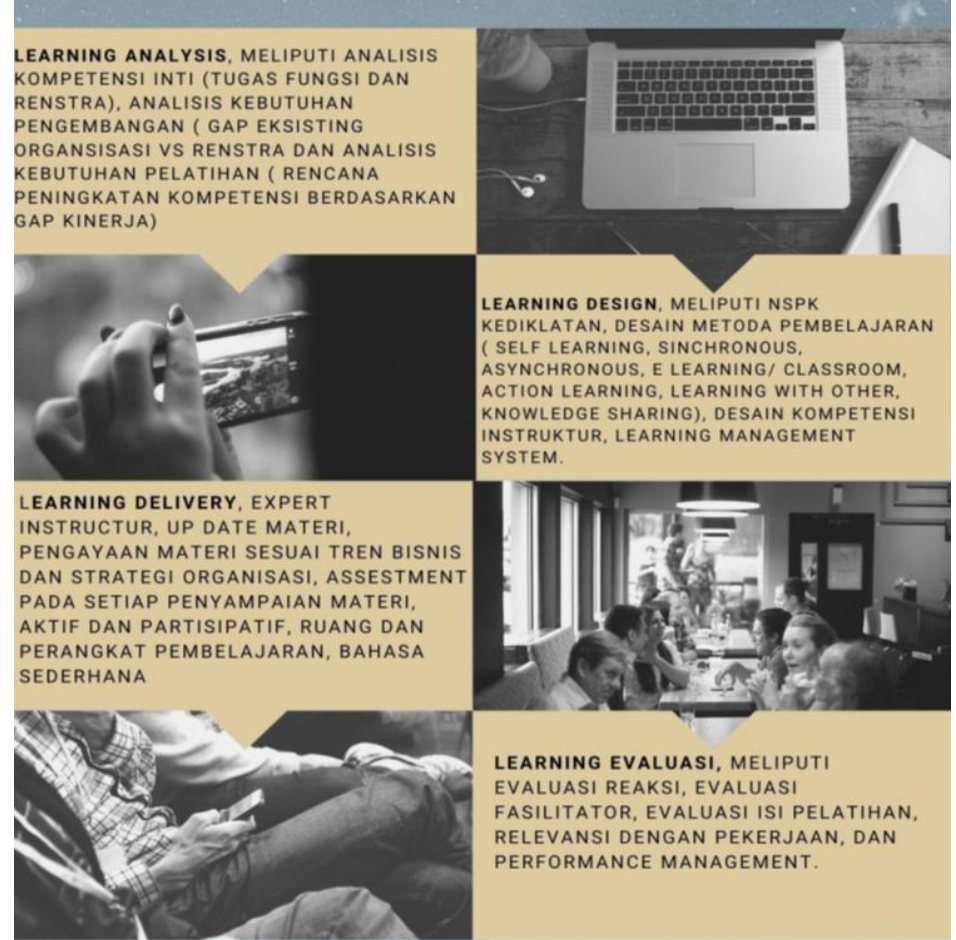

Roadmap PPSDM Aparatur corporate university TOBE 2023

- 2021

Internal : Review standar operational prosedur Training need analysis; review SOP Metode Pembelajaran (pembelajaran terintegrasi), pengembangan Learning management system kearah big data analysis; review SOP Learning Delivery (penyampaian pembelajaran); review SOP Evaluasi ( recording data dan implikasi terhadap performance management)

Eksternal : internalisasi kebutuhan ASN Corporate university di lingkungan Kementerian ESDM; konsolidasi penyusunan analisis kompetensi inti di lingkungan KESDM, pilot project SOP

TNA berdasarkan hasil review learning analysis

- 2022

Penyusunan Pedoman Pengembangan Kompetensi SDM berdasarkan Corporate University

Pilot project program pelatihan berdasarkan alur corporate university

- 2023

Launching PPSDM Aparatur Corporate University 


\section{Kesimpulan}

Kajian literatur dan studi banding dengan PLN Corpu menunjukan adanya perbedaan yang signifikan antara Pendidikan dan Pelatihan konvensional dan corporate university, terutama pada peranan pimpinan dan keterlibatan unit dalam menentukan program pengembangan, yang mampu mendongkrak kinerja organisasi. Parameter-parameter yang digunakan dalam analisis SWOT merupakan pengembangan model ADDIE dalam entitas corporate university. Hasil penelitian ini menunjukan analisis SWOT dalam pengembangan PPSDM Aparatur menuju Corporate University dengan nilai IFAS 1.35 dan EFAS 1.7 perpotongan keduanya berada pada kuadran I. data ini dapat mengarahkan grand strategi pengembangan corporate university dengan memanfaatkan kekuatan internal dan peluang eksternal yang melahirkan kebijakan pertumbuhan agresif. Namun dari hasil evaluasi pasca diklat menunjukan beberapa faktor internal baik dari kekuatan dan kelemahan yang perlu di perbaiki, artinya kekuatan yang ada masih menjadi PR untuk ditingkatkan dan perlu usaha yang cukup besar menuju PPSDM Aparatur corporate university. Hal ini menandakan bahwa analisis SWOT ini dapat menjadi data awal dalam mendesain strategi PPSDM Aparatur corporate university, namun diperlukan expert judgment dalam menilai dan mememenuhi parameter-parameter yang dibutuhkan dalam corporate university tersebut. Kondisi eksisting mengarahkan dalam penyusunan rancangan model dan road map Corporate university PPSDM Aparatur, disusun sebagai wawasan bersama dalam melangkah menuju pencapaian inovasi pengembangan PPSDM Aparatur tahun 2023.

\section{Daftar Pustaka}

Asman. (2018, November 9). Kementerian Pendayagunaan Aparatur Ngara. Retrieved from menpan.go.id.

Chusminah. (2015). Analisis Implementasi Konsep Corporate University dalam Peningkatan Kinerja Karyawan. Widya Clpta Vol. 1 No 1, 87.

Keuangan, K. (2017, Desember 5). https://docplayer.info/72115340-Corporate-universitylangkah-mewujudkan-indonesia-corporate-university-selasa-5-desember-2017.html. Retrieved from Kementerian Keuangan.

Kolo, p. (2013). corporate universities an engine for human capital. The Boston Consulting Group, 12.

Rangkuti, F. (2011). SWOT Balance Score Card. Jakarta: Gramedia.

Wibawa, S. C. (2017). The Design and implementation of an educational multimedia Interactive operational system using Lectora Inspire. Electronics, informatics, and vocational education, 75.

wisnu Satrijono. (2017). indonesias Best practicesc of Corporate University. Jakarta: PT. Swasembada Media Bisnis.

Peraturan Menteri Pendayagunaan Aparatur Negara dan Reformasi Birokrasi Republik Indonesia nomor 3 tahun 2020 tentang manajemen talenta aparatur sipil negara yang menjadikan ASN Corporate University

PPSDM Aparatur 2019, Evaluasi Pasca Diklat Teknis Pelaksana I. 